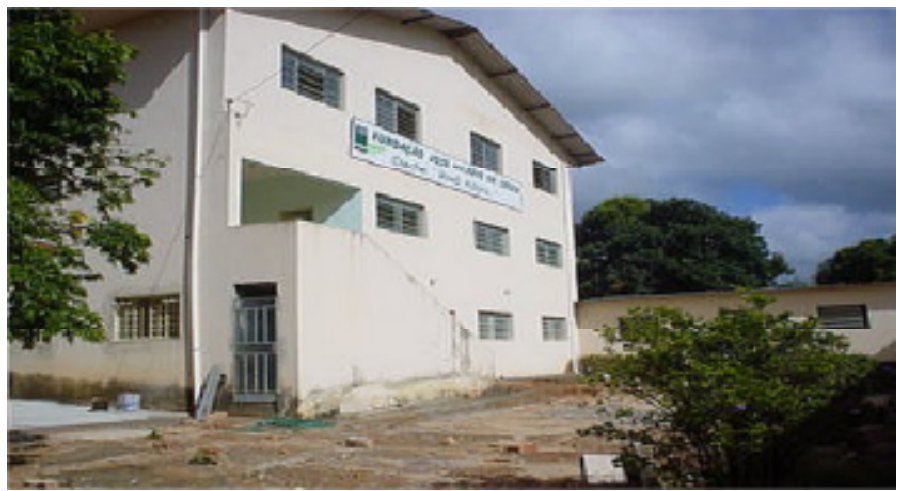

Fotos de Roberto Dineli

\title{
Creche e casa-lar: educação de crianças e adultos
}

\author{
Lúcia Alvim \\ por Maria Antonieta Pereira
}

Lúcia Teixeira Alvim, socióloga (UFMG), especialista em Saúde Pública e em Planejamento e Programação de Serviços de Saúde (ENSP/FIOCRUZ) e Mestre em Sociologia e Economia da Vida Local (Univ. de Paris $X$ - Nanterre). Trabalhou durante longo tempo na implantação do Sistema Único de Saúde -SUS, especialmente na formação e capacitação de recursos humanos nas áreas de política e planejamento de saúde e de gestão de serviços. Atuou também como consultora legislativa nas áreas de saúde, Ação Social e Previdência Social. Após aposentar-se, dedicouse à Fundação José Hilário de Souza, onde ocupou, de Nov/03 a Nov/05, o cargo de Presidente do Conselho Diretor e, a partir de Nov/05, vem ocupando o cargo de Presidente do Conselho Curador.

Maria Antonieta Pereira é professora de Teoria da Literatura e Literatura Comparada na Faculdade de Letras/UFMG. Pós-doutora pela Universidad de Buenos Aires. Autora de vários livros e artigos sobre telas, textos e educação. Pesquisa atual: Tecnologias intelectuais da leitura. Coordenadora do Programa de Ensino, Pesquisa e Extensão A tela e o texto. 


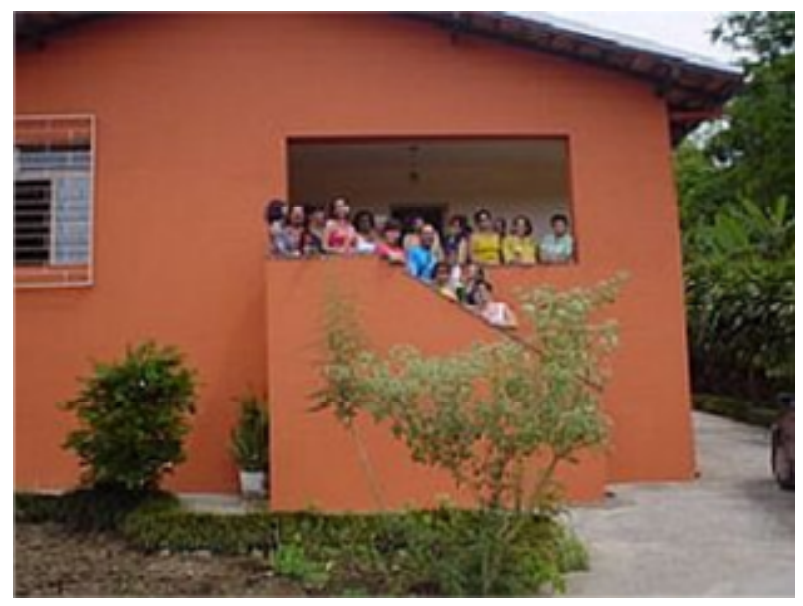

A Fundação José Hilário de Souza - FUNJOHS - é uma entidade sem fins lucrativos, de caráter privado, dotada de autonomia administrativa, técnica e financeira, que se destina a desenvolver ações voltadas para acolhimento, assistência, educação e formação técnico-profissional de crianças e adolescentes em situação de risco (carentes, vítimas de abandono e maus tratos) e para o desenvolvimento social e humano da comunidade local.

Instituída em 16/03/1984, pelo Sr. José Hilário de Souza, com sede em Belo Horizonte, iniciou suas atividades em 1994, dedicando-se em especial ao atendimento de crianças e adolescentes carentes, portadores de deficiência visual, em parceria com a APADV (Associação de Pais e Amigos dos Deficientes Visuais). Foi declarada de Utilidade Pública no Estado de Minas Gerais, pela Lei no 12.195, de 13/06/1996.

Paralelamente às atividades desenvolvidas em Belo Horizonte, o instituidor adquiriu um terreno com área de $15.600 \mathrm{~m}^{2}$, situado no Distrito de Vera Cruz de Minas, em Pedro Leopoldo, onde foi construindo, ao longo do tempo, várias edificações destinadas ao abrigo de crianças carentes. As edificações da FUNJOHS somam hoje uma área de mais de $1.300 \mathrm{~m}^{2}$, distribuídas em um edificio com 03 pavimentos, casas, galpões, pátios e uma capela.

Tendo em vista a existência desse conjunto de edificações no município, a Promotoria Pública tomou medidas visando à transferência da sede da Fundação para Pedro Leopoldo, o que ocorreu em setembro de 2001. Em 04 de novembro de 2002, pela Lei no 2.677, a Fundação foi declarada de Utilidade Pública Municipal.

As edificações, pelo fato de estarem em desuso há longos anos, encontravam-se muito deterioradas e foi necessário implementar uma ampla reforma para recuperá-las e adequá-las às normas da Vigilância Sanitária e da política de assistência à criança e 
ao adolescente. Após as reformas, realizadas com recursos do FIA - Fundo da Infância e da Adolescência - e doações de material de construção por empresas locais, conseguimos viabilizar a implantação de um abrigo, segundo as diretrizes do "Programa Casa Lar" da SEDESE, e também de uma creche para crianças carentes, denominada "Creche Vovô Hilário", que foram inaugurados em dezembro último.

A "Casa Lar" destina-se a acolher 15 crianças de ambos os sexos, com no máximo 12 anos de idade, em situação de risco pessoal e social, sob medida de proteção/abrigo, garantindo seus direitos fundamentais. Acolhe crianças de todo o município. A Creche atende a 30 crianças de 03 a 06 anos, de ambos os sexos, apenas da região de Vera Cruz, em regime de semi-internato, visando a promover o seu desenvolvimento nas diversas dimensões da formação humana, completar a ação da família e atender à legislação atual no que se refere à educação infantil.

As atividades da FUNJOHS são norteadas por princípios humanos e éticos. O Plano de Ação é sustentado pela Leis Federais 8.069/90 (Estatuto da Criança e do Adolescente - ECA) e 9.394/96 (Lei de Diretrizes e Bases da Educação Nacional/LDB), e também pela Lei Orgânica da Assistência Social (LOAS) .

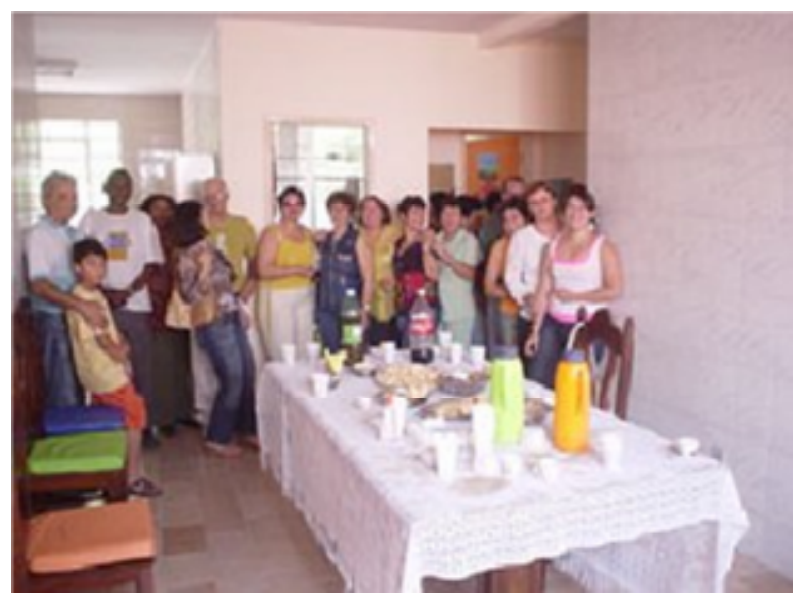

\section{Maria Antonieta Pereira - Quais são os objetivos educacionais da Fundação?}

Lúcia Alvim - O nosso objetivo mais geral é educar para a cidadania, infundindo nas crianças valores éticos e morais e estimulando seu senso de responsabilidade e de respeito pelo outro, para que possam se tornar cidadãos de bem e vir a ter uma inserção positiva na sociedade. Numa perspectiva mais imediata, procuramos desenvolver hábitos e habilidades, despertar interesse pelos estudos e por atividades esportivas 
e culturais. Buscamos, enfim, o desenvolvimento das crianças nas diversas dimensões da formação humana.

\section{Os profissionais encarregados de realizar esses objetivos enfrentam quais dificuldades? Há experiências produtivas sendo construídas?}

Há dificuldades decorrentes de lidarmos com crianças em situação de risco, em especial as que se encontram em regime de abrigamento, que tiveram uma experiência vivencial de pobreza, abandono, conflitos e traumas familiares. Essas crianças quase sempre demonstram rebeldia e resistência para conviver com limites e rotinas, bem como para assimilar hábitos de organização, respeito e disciplina. Em função disso, um dos grandes problemas experimentados pelas monitoras, responsáveis pela educação das crianças, consiste em definir até que ponto podem e devem impor limites, bem como a forma mais adequada de fazê-lo. Ou seja, é difícil definir o ponto limítrofe entre a ação restritiva necessária à consolidação do processo educativo e aquela que assume um caráter de pura negação ou de prepotência.

Por outro lado, a instituição optou por recrutar monitoras na própria localidade, no intuito de contribuir para o incremento da renda das famílias e para a valorização e o estímulo da comunidade. No entanto, o distrito onde se localiza a Fundação, de características tipicamente rurais, não dispõe de mão de obra qualificada. Selecionamos jovens que, embora sem a formação desejada, nos pareceram ter um perfil adequado para lidar com crianças e disposição para enfrentar dificuldades. E assumimos o desafio de treiná-las e formá-las no próprio processo educativo das crianças. Estamos, assim, construindo uma experiência que constitui um desafio duplo: educar as crianças e formar as monitoras num processo único e concomitante.

Vocês estão articulando algum tipo de produção coletiva de conhecimento, em termos pedagógicos, gerenciais, grupais etc.? Trata-se de uma experiência inovadora?

Se se entende "produção coletiva de conhecimento" como a criação de um corpo de conhecimento sistematizado e organizado, de forma a poder disponibilizá-lo para uso de terceiros, certamente não. Estamos muito no começo de nossas atividades e não dispomos ainda de experiências suficientemente amadurecidas para fazê-lo.

No entanto, estamos vivenciando um processo pedagógico sui generis, criando alternativas de gerenciamento colegiado, bem 
como buscando desenvolver na equipe um espírito de cooperação coletiva, que possa se traduzir em aperfeiçoamento das práticas. E, na medida do possível, estamos buscando instrumentalizar funcionários e gerentes para, juntos, conseguirmos identificar os caminhos mais adequados, tanto no que se refere aos processos grupais, quanto aos pedagógicos. É nessa perspectiva, inclusive, que alguns de nossos gerentes se inscreveram no curso "Teorias de rede, ensino de leitura e grupalismo", oferecido na Faculdade de Letras da UFMG pelo Programa A tela e o texto e pelo Núcleo de Psicanálise e Práticas Institucionais. Também nesse contexto é que a Profa. Maria Antonieta Pereira, coordenadora do Programa A tela e o texto, gentilmente ministrou na Fundação o curso "Educação e Leitura de Telas e Textos", que discutiu o conceito de educação, os papéis do educador e do educando e os problemas da educação nos dias de hoje.

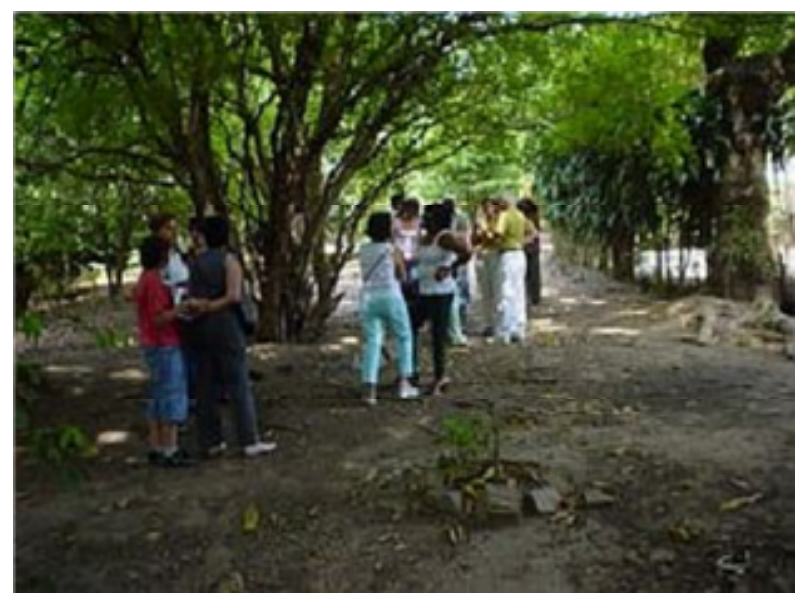

Paulo Freire dizia que a leitura do texto deveria estar relacionada à leitura do mundo e vice-versa. Tendo em vista o público atendido pela Fundação, como essa proposta poderia ser levada adiante?

É preciso considerar que nossas crianças, como a comunidade de Vera Cruz em geral, têm pouco ou nenhum convívio com a literatura. A localidade não dispõe de biblioteca e a população não tem hábito de leitura e nem possibilidade de acesso aos livros.

Nesse contexto, o primeiro esforço a ser feito é no sentido de disponibilizar livros e induzir crianças e monitoras a se interessarem por eles. Para tanto, creio ser necessário trabalhar inicialmente textos simples e agradáveis. A literatura infantil é rica em textos dessa natureza. Embora na maioria das vezes retratem situações radicalmente diferentes das vividas pela nossas crianças, a televisão já se encarregou de inseri-las no imaginário infantil. 
No caso das monitoras e da população em geral, a situação é diferente e faz-se necessário encontrar textos que possam se reportar, em alguma medida, à realidade em que vivem ou a seus valores e à sua visão de mundo. Uma alternativa que nos pareceu interessante para estimular a leitura foi a apresentada pela Prof. Maria Antonieta Pereira, de exibir e discutir alguns filmes estrategicamente selecionados $e$, em seguida, distribuir textos relacionados a eles.

\section{Que tipo de articulação a Fundação está construindo com a comunidade de Vera Cruz?}

Estamos em contato com os grupos organizados de Vera Cruz, como as associações de moradores, o Clube de Mães, o Grupo da Terceira Idade, a Sociedade São Vicente de Paula, a Pastoral de Jovens, entre outros. Esses grupos têm utilizado o espaço da Fundação para a realização de missas, encontros comemorativos e eventos em geral e têm colaborado conosco na execução de algumas atividades. Exemplo disso foi o levantamento de demanda para a creche, coordenado por nós e executado por membros desses grupos, com aplicação de questionários em todas as residências do distrito.

Mas a Fundação, tendo cumprido sua meta para o biênio 2003/2005 - a instalação da Casa Lar e da Creche - pretende, a partir deste ano, ampliar suas atividades, desenvolvendo projetos voltados para a comunidade, em especial para os jovens, que têm pouca ou nenhuma alternativa de formação profissional, de esporte, lazer ou cultura. Estão previstos projetos de inclusão digital e de formação profissional nas áreas de floricultura e jardinagem, ordenha mecânica e tratamento de eqüinos, em parceria com agroindústrias e fazendas da região.

Além disso, estamos programando, juntamente com uma das associações de moradores da região, desenvolver projetos de geração de renda, envolvendo cursos e atividades de culinária, bordado e artesanato. Aproveitando esse contato mais sistemático com a comunidade, pretendemos montar também programas voltados para elevar seu nível de conhecimento e informação. É nessa perspectiva que, em parceria com $A$ tela $e$ o texto, vamos apresentar em breve uma Mostra de Cinema e debater os filmes exibidos. 


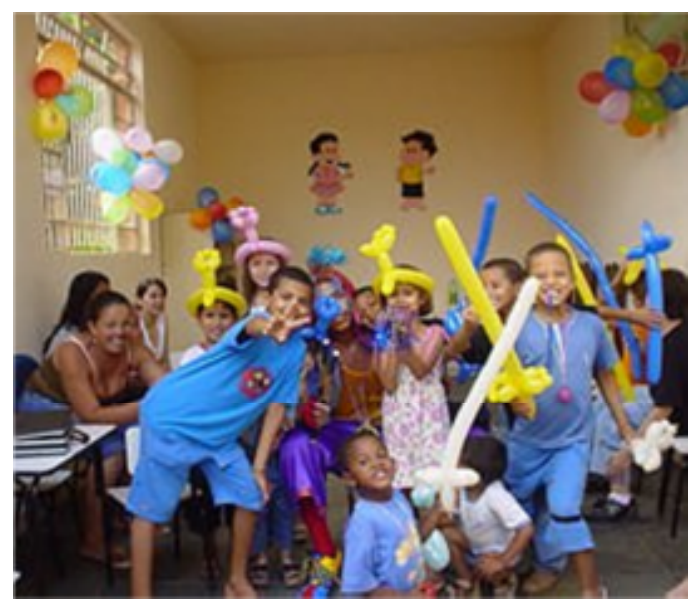

\section{Para contato:}

Fundação José Hilário de Souza

Rua Várzea Formosa, 03 - Vera Cruz de Minas

Pedro Leopoldo - MG - CEP 33600-000

Fones: 3662-0471/2662-0472 